\title{
Si-Based Anode Materials for Li-Ion Batteries: A Mini Review
}

\author{
Delong Ma $\cdot$ Zhanyi Cao $\cdot$ Anming Hu
}

Received: 3 April 2014/Revised: 24 May 2014/Accepted: 10 June 2014/Published online: 27 September 2014

(C) The Author(s) 2014. This article is published with open access at Springerlink.com

\begin{abstract}
Si has been considered as one of the most attractive anode materials for Li-ion batteries (LIBs) because of its high gravimetric and volumetric capacity. Importantly, it is also abundant, cheap, and environmentally benign. In this review, we summarized the recent progress in developments of Si anode materials. First, the electrochemical reaction and failure are outlined, and then, we summarized various methods for improving the battery performance, including those of nanostructuring, alloying, forming hierarchic structures, and using suitable binders. We hope that this review can be of benefit to more intensive investigation of Si-based anode materials.
\end{abstract}

Keywords Li-ion batteries $\cdot$ Anode $\cdot \mathrm{Si} \cdot$ High capacity $\cdot$ Nanomaterials

\section{Introduction}

In the last two decades, the Li-ion batteries (LIBs) have successfully captured the portable electronic market. However, when it is proposed to conquer the upcoming markets of electric vehicles, storage of energy from renewable energy sources, such as photovoltaic plants and/ or wind turbines and other KWh levels load, great improvements in storage capacity, which is currently mainly limited by their electrode materials, are urgently needed [1-5]. It is well known that the commercial

\section{D. $\mathrm{Ma} \cdot \mathrm{A} . \mathrm{Hu}(\bowtie)$}

Institute of Laser Engineering, Beijing University of

Technology, 100 Pingle Yuan, Chaoyang District,

Beijing 100124, People's Republic of China

e-mail: anminghu@bjut.edu.cn

D. Ma $\cdot$ Z. Cao

Key Laboratory of Automobile Materials, Ministry of Education and School of Materials Science and Engineering, Jilin

University, Changchun 130012, People's Republic of China

A. $\mathrm{Hu}$

Department of Mechanical, Aerospace and Biomedical Engineering, University of Tennessee, 1512 Middle Drive, Knoxville, TN 37996-2210, USA graphite anode cannot meet these challenges due to its low theoretical capacity ( $372 \mathrm{mAh}^{-1}$ ). There is a consensus that the breakthrough in capacity can be achieved by moving from classical intercalation reaction to alloying reaction because the alloying reaction can store more $\mathrm{Li}$ compared with intercalation reaction. For example, Li can react with $\mathrm{Si}$ to form $\mathrm{Li}_{22} \mathrm{Si}_{5}$ alloy, but with graphite only, to form $\mathrm{LiC}_{6}$ alloy. Since Dey demonstrated that $\mathrm{Li}$ metal can electrochemically alloy with other metals ( $\mathrm{Sn}, \mathrm{Pb}, \mathrm{Al}$, $\mathrm{Au}, \mathrm{Pt}, \mathrm{Zn}, \mathrm{Ag}, \mathrm{Mg}$, and $\mathrm{Cd}$ ) at room temperature [6], Lialloying reactions with metallic or semi-metallic elements and various compounds have been investigated during the past few decades, such as $\mathrm{Sn}, \mathrm{P}, \mathrm{Ge}, \mathrm{Pb}$, and $\mathrm{Sb}$. Wen et al. showed that $\mathrm{Sn}$ reacted with lithium to yield different Li-Sn phases: $\mathrm{Li}_{2} \mathrm{Sn}_{5}, \mathrm{LiSn}, \mathrm{Li}_{7} \mathrm{Sn}_{3}, \mathrm{Li}_{5} \mathrm{Sn}_{2}, \mathrm{Li}_{13} \mathrm{Sn}_{5}, \mathrm{Li}_{7}$ $\mathrm{Sn}_{2}$, and $\mathrm{Li}_{22} \mathrm{Sn}_{5}$. A black $\mathrm{P} / \mathrm{C}$ nanocomposite also showed high capacity (about 2,000 $\mathrm{mAh} \mathrm{g}^{-1}$ ) [3]. Among the various Li alloy elements, $\mathrm{Si}$ has been considered as one of the most attractive anode materials for LIBs, not only because of its high gravimetric $\left(4,200 \mathrm{mAh} \mathrm{g}^{-1}\right)$ and vol-

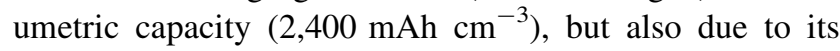
abundance, cheapness, and environmentally benign property, as shown in Table 1. However, it suffers from fast capacity fading, which greatly hampers the application of $\mathrm{Si}$ anode materials. 
Table 1 Property of Li alloy elements [3]

\begin{tabular}{lccccc}
\hline Element & $\begin{array}{l}\text { Gravimetric } \\
\text { capacity } \\
\left(\mathrm{mAh} \mathrm{g}^{-1}\right)\end{array}$ & $\begin{array}{l}\text { Volumetric } \\
\text { capacity }(\mathrm{mAh} \\
\left.\mathrm{cm}^{-3}\right)\end{array}$ & Cost & Toxicity & Safety \\
\hline $\mathrm{Si}$ & 4,200 & 2,400 & Low & No & High \\
$\mathrm{C}$ & 372 & 890 & Low & No & Low \\
$\mathrm{Ge}$ & 1,568 & 2,300 & High & High & High \\
$\mathrm{Sn}$ & 990 & 2,020 & Low & No & High \\
$\mathrm{P}$ & 2,600 & 2,250 & Low & High & Low \\
$\mathrm{Sb}$ & 660 & 1,890 & Low & High & Low \\
$\mathrm{Pb}$ & 549 & 1,790 & Low & High & Low \\
\hline
\end{tabular}

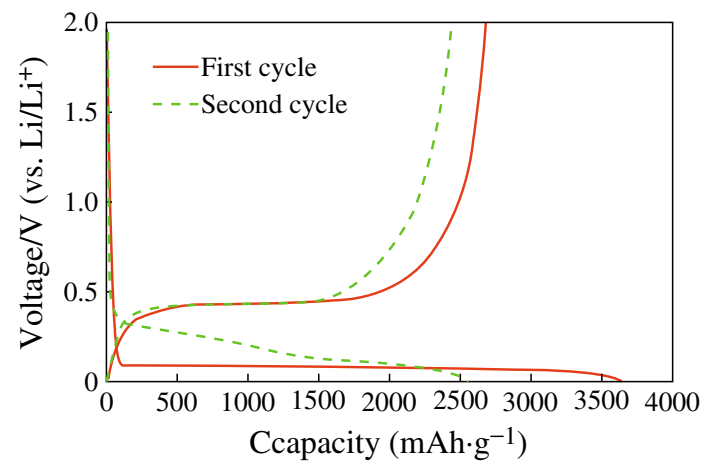

Fig. 1 Voltage profiles of $\mathrm{Si}$ powder electrode for the first and second discharge/charge cycles [18]

\subsection{The Mechanism of Electrochemical Lithiation}

LIBs are mainly composed of anode (generally graphite), a carbonate-based organic electrolyte, and a cathode (generally $\mathrm{LiCoO}_{2}$ ). Li ions are intercalated and deintercalated between graphite and $\mathrm{LiCoO}_{2}$ through the electrolyte during discharge and charge. The theoretical capacities of anode and cathode are $372 \mathrm{mAh} \mathrm{g}^{-1}$ (graphite) and less than $160 \mathrm{mAh} \mathrm{g}^{-1}\left(\mathrm{LiCoO}_{2}\right)$, respectively, which are too low, especially for anode material. $\mathrm{Si}$ anode is very attractive because of its high theoretical capacity of $4,200 \mathrm{mAh} \mathrm{g}^{-1}$ which is 10 times more than that of commercial graphite [3]. Moreover, the discharging potential is about $0.2 \mathrm{~V}$ with respect to $\mathrm{Li} / \mathrm{Li}^{+}$, which is lower than most of other alloy-type and metal oxide anodes [7]. Furthermore, it is safer and stabler than graphite (lithiated silicon is more stable in typical electrolytes than lithiated graphite) [8].

The mechanism of electrochemical lithiation of $\mathrm{Si}$ is critical to improve the performance of $\mathrm{Si}$ anode, which has been investigated by several groups [9-16]. It is found that the reactions follow the equilibrium Li-Si binary phase

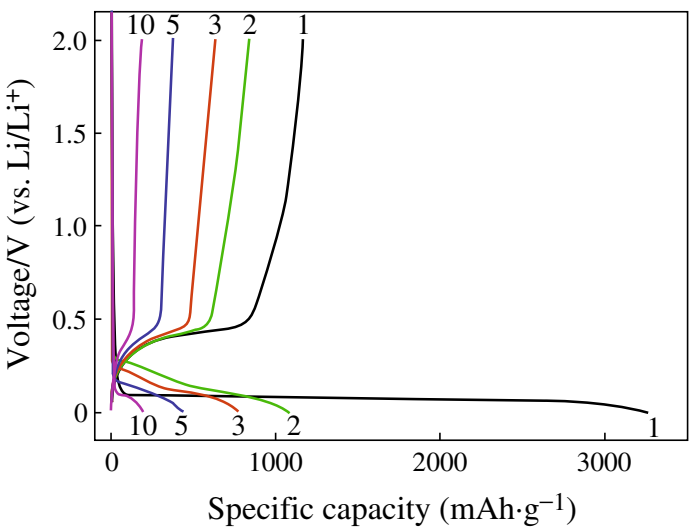

Fig. 2 Charge-discharge voltage profiles of Si powder anode [16]

diagram at high temperature, forming different intermetallic compounds and showing distinct voltage plateaus for each two-phase region [17]. However, there is only a twophase region at about $0.1 \mathrm{~V}$ at room temperature during first discharge process [18], as shown in Fig. 1. It should be noted that the two-phase region disappears after first cycle. In order to find out the lithiation mechanism, X-ray diffraction (XRD) analysis was performed to investigate the phase transition [13-15], and the reaction mechanism is explained as follows:

During discharge

$$
\begin{aligned}
& \mathrm{Si}(\text { crystalline })+x \mathrm{Li}^{+}+x \mathrm{e}^{-} \rightarrow \mathrm{Li}_{x} \mathrm{Si} \text { (amorphous) } \\
& \quad+(3.75-x) \mathrm{Li}^{+}+(3.75-x) \mathrm{e}^{-} \\
& \rightarrow \mathrm{Li}_{15} \mathrm{Si}_{4} \text { (crystalline) }
\end{aligned}
$$

During charge

$$
\begin{aligned}
& \mathrm{Li}_{15} \mathrm{Si}_{4}(\text { crystalline }) \rightarrow \mathrm{Si}(\text { amorphous })+y \mathrm{Li}^{+}+y \mathrm{e}^{-} \\
& \quad+\mathrm{Li}_{15} \mathrm{Si}_{4}(\text { residual })
\end{aligned}
$$

In the two-phase region, crystalline $\mathrm{Si}$ becomes amorphous $\mathrm{Li}-\mathrm{Si}$ alloy during the first lithiation (1), and the highly lithiated amorphous $\mathrm{Li}_{x} \mathrm{Si}$ phase is suddenly found to crystallize into $\mathrm{Li}_{15} \mathrm{Si}_{4}$ phase around $60 \mathrm{mV}$ (vs. $\mathrm{Li} / \mathrm{Li}^{+}$) (2). Another two-phase region appears during the first delithiation process, and the final product is amorphous $\mathrm{Si}$ (3). There are also amounts of residual $\mathrm{Li}_{15} \mathrm{Si}_{4}$ phase after the first delithiation, which can be avoided if the potential of the $\mathrm{Si}$ electrode is controlled above $70 \mathrm{mV}$ during cycling. When $\mathrm{Li}$ ions react with the amorphous $\mathrm{Si}$ during the second cycle, the two-phase region disappears, and sloping voltage plateaus are observed, which indicates single-phase region. After the second cycle, reactions (2) and (3) were repeated, show the above features repeatedly, and reversible capacity faded quickly. 
Fig. 3 Schematic of morphologic changes that occur in Si during electrochemical cycling [20]

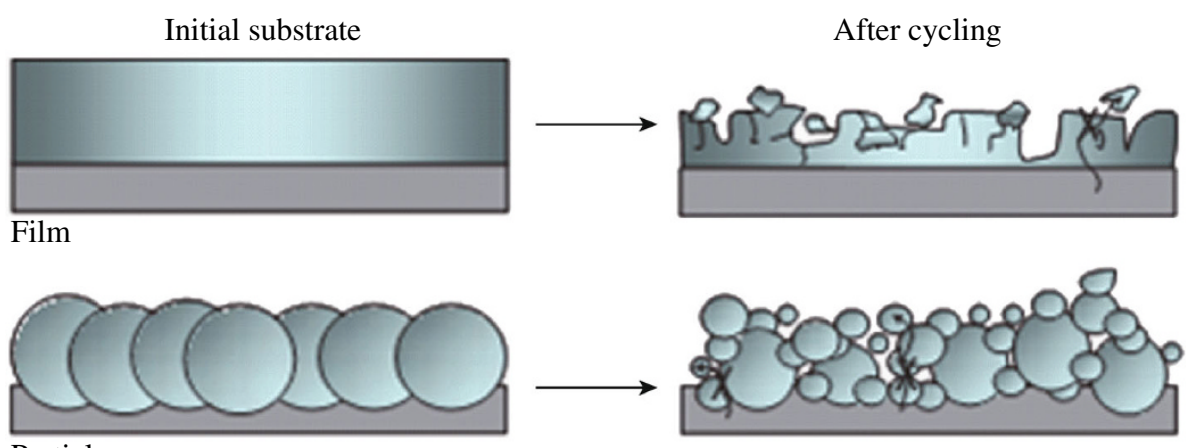

Particles

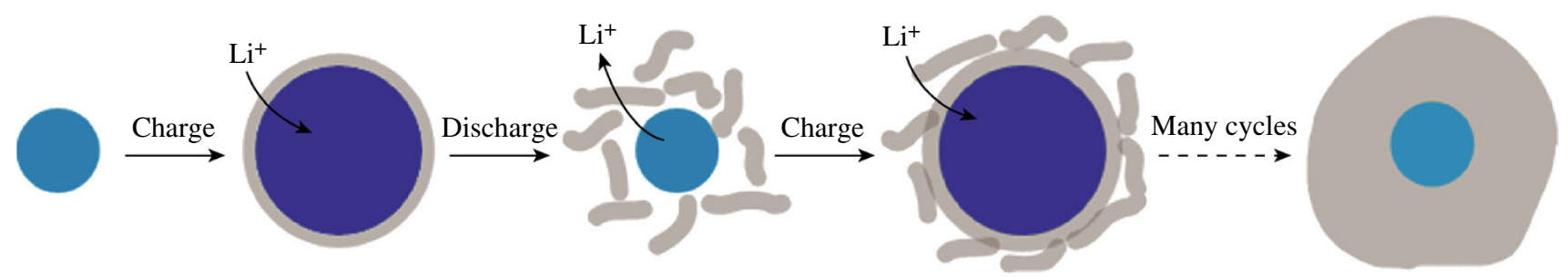

Fig. 4 Schematic of SEI formation on silicon surfaces [21]

\subsection{The Failure Mechanism}

Although Si has the highest theoretical capacity, its cycling performance is very poor. Figure 2 shows the charge-discharge profiles of Si powder anode at a current density of $100 \mathrm{~mA} \mathrm{~g}^{-1}$. It could be found that a large amount of irreversible capacity appears in the first cycle. The first discharging capacity is about $3,260 \mathrm{mAh} \mathrm{g}^{-1}$ but that of the charging is only $1,170 \mathrm{mAh} \mathrm{g}^{-1}$. After 10 cycles, only very low capacity (about $200 \mathrm{mAh} \mathrm{g}^{-1}$ ) can be retained. To understand the reasons for the poor cycling stability of $\mathrm{Si}$ anode, the failure mechanism has been investigated by several groups $[16,19]$. The conclusions can be drawn as follows:

a. The large change in the volume of Si anodes, which increases internal resistance and loss of contact area between $\mathrm{Si}$ and conductive materials, is considered to be the main reason for their rapid capacity loss. Figure 3 shows the schematic of morphologic changes that occur in Si during electrochemical cycling [20]. The volume of $\mathrm{Si}$ anodes changes by about $400 \%$ during cycling. As a result, Si films and particles tend to undergo pulverization during cycling. Most of the material loses contact with the current collector, resulting in poor transport of electrons.

b. Solid electrolyte interphase (SEI) stability at the interface between the silicon and the liquid electrolyte is also responsible for the failure of the $\mathrm{Si}$ anode. The SEI layer is formed during battery discharging, due to electrolyte decomposition on the surface of anode at the low potential. As shown in Fig. 4, a thin layer of SEI is formed in the lithiated and expanded state [21]. During delithiation, the Si particle shrinks, and the SEI layer breaks down into separate pieces, and fresh $\mathrm{Si}$ surface is exposed to the electrolyte. In later cycles, new SEI layer continues to be formed on the newly exposed silicon surfaces. The SEI is an electronic insulator but a $\mathrm{Li}$-ion conductor, and so the growth of the SEI layer is eventually terminated at a certain thickness. The thick SEI layer is harmful for the cycle life, because it can cause a rise of the electrode impedance/polarization and decrease of the electrode's electrochemical reactivity. As discussed above, a large volume change and unstable formation of SEI film are the main issues for the failure of $\mathrm{Si}$ anode.

\section{The Methods to Improve the Battery Performance}

\subsection{Si Nanostructures}

Tremendous efforts have been made to improve the batteries performance of $\mathrm{Si}$ anode. In order to overcome the volume change during electrochemical reaction, many researches are focused on accommodating the volume changes in the earlier studies. Nanomaterials have the genuine potential to make a significant impact on the electrochemical performance of $\mathrm{Si}$ anode [22], as their reduced dimensions enable far higher intercalation/deintercalation rates. In addition, the volume change can be 
also buffered after downsizing the Si particle to nano-size. The significance of nano-sized Si on battery performance was demonstrated by several groups. Li et al. reported that a nano-Si $(78 \mathrm{~nm})$ powder anode showed better capacity retention than bulk $\mathrm{Si}$ powder [23]. Kim et al. also synthesized $\mathrm{Si}$ nanoparticles with various sizes $(5,10$, and
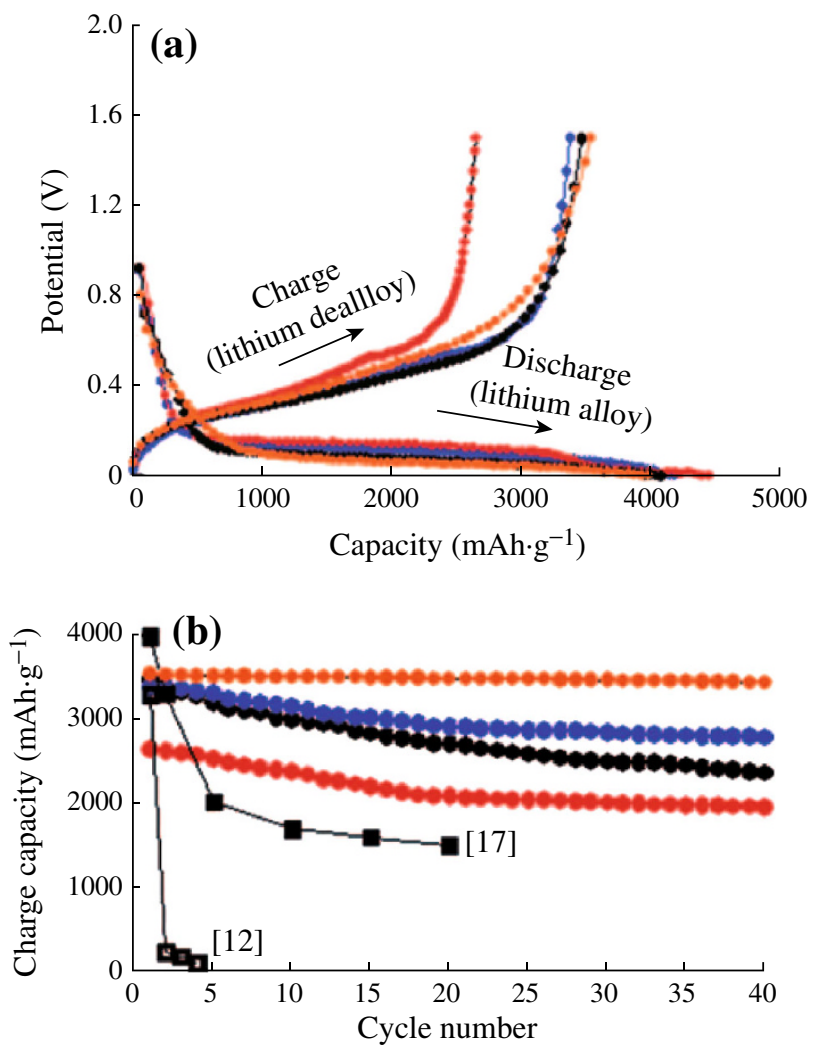

Fig. 5 a Voltage profiles of 5, 10, and 20-nm-sized Si and 10-nmsized Si after carbon coating during the first cycle in coin-type halfcells at a rate of $0.2 \mathrm{C}$ between 0 and $1.5 \mathrm{~V}$. b Plot of charge capacity versus cycle number (red: $5 \mathrm{~nm}$, blue: $10 \mathrm{~nm}$, orange: $10 \mathrm{~nm}$ after carbon coating, black circles: $20 \mathrm{~nm}$ ) [24]. (Color figure online)
$20 \mathrm{~nm}$ ) and studied their battery performance [24]. The results indicated that $10-\mathrm{nm}$-sized $\mathrm{Si}$ showed the highest capacity retention among the samples, as shown in Fig. 5.
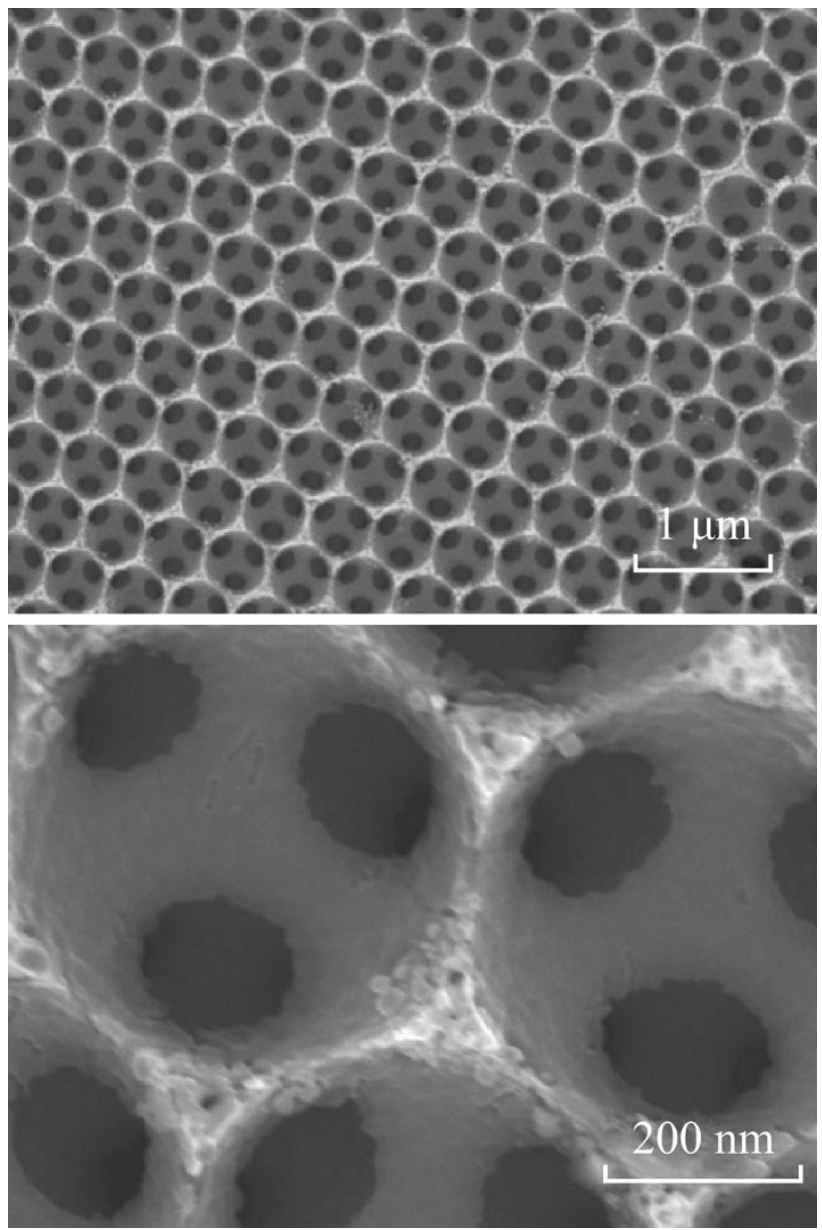

Fig. 7 SEM images of the nanocrystalline Si inverse opal structure [36] (a)

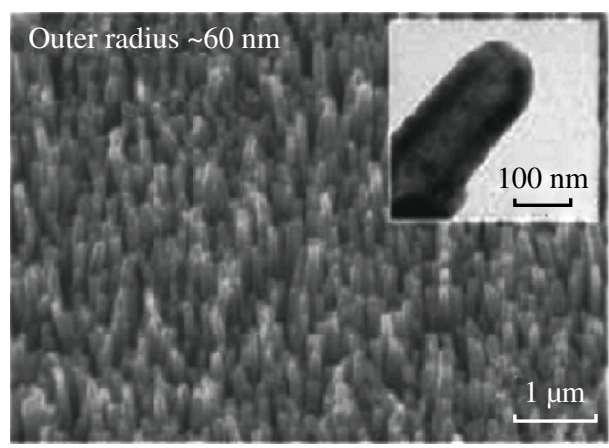

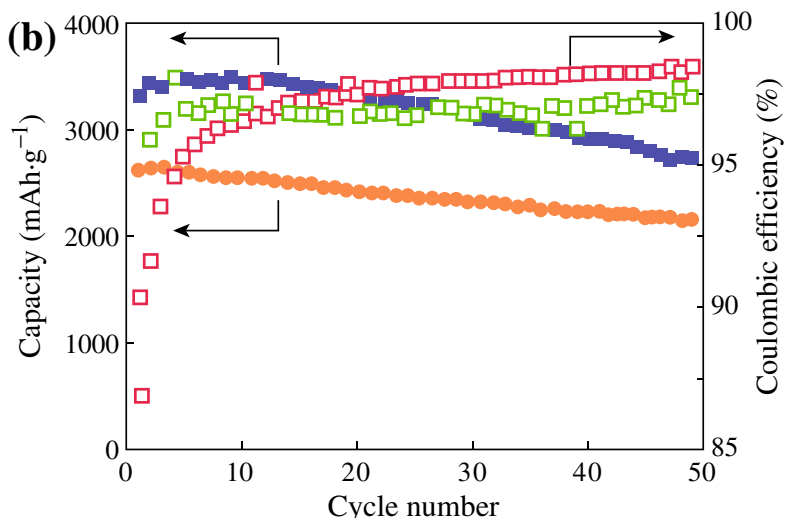

Fig. 6 a SEM and TEM images (insets) of the sealed tip of a Si nanotubes. b Cycle performances at a rate of 0.05 and $0.2 \mathrm{C}$ (square: $0.05 \mathrm{C}$, circle: 0.2 C) [25] 


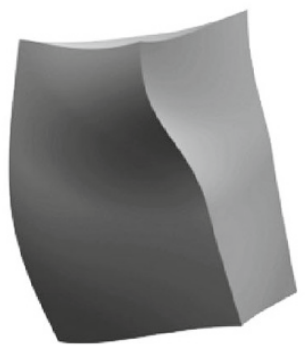

Bulk Si
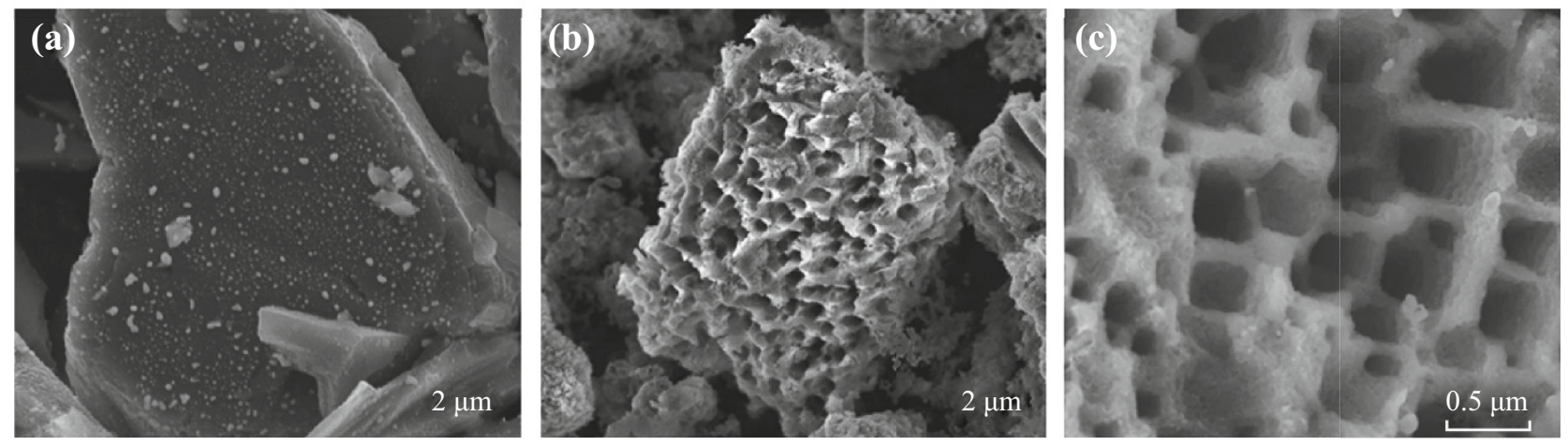

Fig. 8 Upper: schematic illustration of the preparation of macroporous Si powders. Ag nanoparticles were deposited onto the surface of bulk silicon via a galvanic reaction, and subsequently, the Ag-deposited Si was chemically etched to make 3D porous Si particles. Lower: a SEM image of Ag-deposited Si. b SEM image of chemically etched Si. c Magnified SEM image of samples seen in (b) [37]

One-dimensional (1D) nanowires and nanotubes are also intriguing structures with good cycle stability. Cui et al. synthesized Si nanowires which were grown directly on the metallic current collector substrate [20]. The limited nanowire diameter allows for better accommodation of the large volume change and provides $1 \mathrm{D}$ electronic pathways allowing for efficient charge transport. The Si nanowires display high capacities at higher current density. Even at the $1 \mathrm{C}$ rate, the capacities remain $2,100 \mathrm{mAh} \mathrm{g}^{-1}$, and a reversible capacity of over $3,000 \mathrm{mAh} \mathrm{g}^{-1}$ is maintained after 10 cycles. An array of sealed $\mathrm{Si}$ nanotubes is also prepared by $\mathrm{CVD}$ of $\mathrm{Si}$ on to $\mathrm{ZnO}$ nanorods and selective removal of $\mathrm{ZnO}$ (see Fig. 6) [25]. It shows discharge capacities of 3,360 and 2,500 $\mathrm{mAh} \mathrm{g}^{-1}$ at the rates of 0.05 and $0.2 \mathrm{C}$ respectively, and high capacity retentions (about 81 and $82 \%$ at 0.05 and $0.2 \mathrm{C}$, respectively) after 50 cycles.

Two-dimensional (2D) Si thin film is another promising nanostructure with improved cycle stability and rate capabilities, which can minimize the volume variation and retain structural integrity [26-29]. Of course, the battery performance depends on the film thickness as thinner films deliver larger accommodation capacity. For example, a 50-nm-thick Si film is found to deliver a higher discharge capacity and better cycling performance compared with 150-nm-thick Si film [26]. Although Si thin film offers high specific capacity, good capacity retention and fast charge/ discharge rate, the practical application is hampered because of their prohibitively high synthesis costs and low active material content.

Recently, three-dimensionally macroporous (3DM) structure materials used in LIBs have attracted more attention, due to their special nature [30-35], as shown in Fig. 7. First, the wall thicknesses are on the order of nanometers to tens of nanometers, which can shorten both electronic and ionic pathways. Second, macropores with a size range of several hundred nanometers enable easy infiltration of electrolyte and fast liquid-phase Li ion diffusion, reducing the concentration polarization and increasing rate performance and capacity of the cell. Third, the continuous network of electrode material may provide better electrical conductivity than aggregates of loosely connected particles. Finally, macroporosity should help in accommodating volume change during cycling without losing the structural integrity of the electrode. Esmanski et al. synthesized several types of silicon-based inverseopal films and studied their electrochemical performances [36]. These electrodes demonstrated significant improvement both in capacity retentions and rate capabilities.

Bang et al. reported a simple route for synthesizing 3DM bulk Si materials by combining an electroless metal deposition via a galvanic displacement reaction, with a metal-assisted chemical etching process using commercially available bulk Si powders (Fig. 8). The as-prepared materials exhibited a high reversible capacity of approximately $2,050 \mathrm{mAh} \mathrm{g}^{-1}$ with a remarkable initial coulombic 

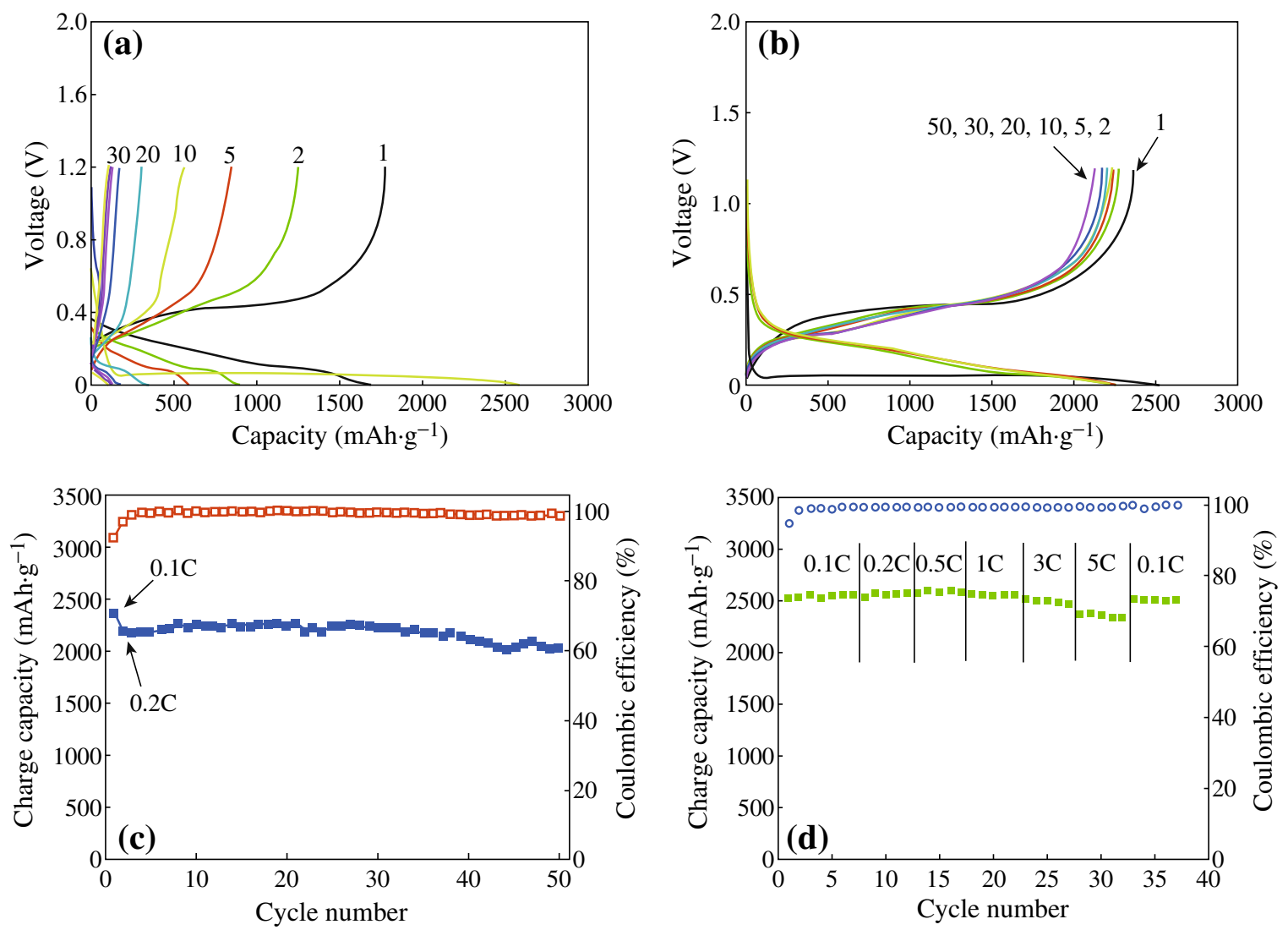

Fig. 9 Electrochemical evaluation of macroporous $\mathrm{Si}$ and the carbon-coated macroporous Si. a Voltage profiles of chemically etched Si anodes at $0.1 \mathrm{C}$ rate between 0.005 and $1.2 \mathrm{~V}$ in coin-type half cell. b Voltage profiles of the carbon-coated porous Si anodes at $0.1 \mathrm{C}$ (the first cycle) and $0.2 \mathrm{C}$ (2nd-50th cycles) in the same conditions. $\mathbf{c}$ Plot of charge capacity versus cycle number obtained from voltage profiles seen in (b). $\mathbf{d}$ Rate capabilities of the carbon-coated porous $\mathrm{Si}$ anodes [37]

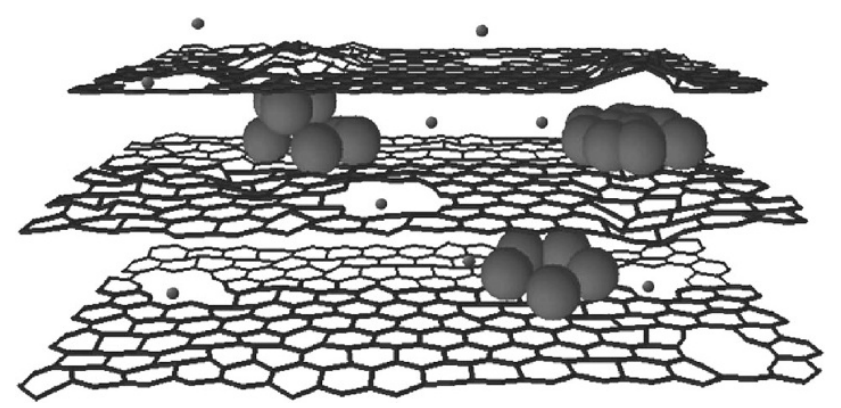

Fig. 10 The schematic drawing of a section of a composite electrode material constructed with a graphitic scaffold with in-plane carbon vacancy defects [51]

efficiency of $94.4 \%$, and stable cycling retention (Fig. 9) [37].

\section{$2.2 \mathrm{Si} / \mathrm{M}$ Composites (M: Active/inactive Conductive Materials)}

In comparison with bulk $\mathrm{Si}$ materials, the pristine nanostructures of Si have shown improved capacity retention.
However, the nano-sized $\mathrm{Si}$ anode materials are still plagued with the intrinsic low electrical conductivity of $\mathrm{Si}$. Liu et al. have shown that increasing the conducting additive content played an important role in improving battery performance of the electrodes [38].

Several groups have paid attention to some intermetallic compounds containing $\mathrm{Si}$ as anode materials, such as $\mathrm{Mg}_{2} \mathrm{Si}, \mathrm{CaSi}_{2}, \mathrm{NiSi}, \mathrm{FeSi}, \mathrm{CoSi}_{2}, \mathrm{FeSi}_{2}$, and $\mathrm{NiSi}_{2}$ [12, 3944]. For example, the first discharge capacity of NiSi is shown to be $1,180 \mathrm{mAh} \mathrm{g}^{-1}$, which corresponds to the insertion of $3.82 \mathrm{~mol} \mathrm{Li}$, and the initial coulombic efficiency was $80 \%$. Here, $\mathrm{Ni}$ is expected to act as a buffering and conductive matrix for the formation of $\mathrm{Li}_{x} \mathrm{Si}$ in the subsequent cycles. Nano-Si/polypyrrole (PPy) composites are prepared by HEMM and chemical polymerization, respectively [45]. It is found that the PPy conducting polymer matrix is effectively acting to increase the electrical conductivity and buffer the volume change.

Recently, some works on $\mathrm{Si}-\mathrm{C}$ composites have been reported. When graphite and pyrolyzed carbon are used as matrices, some promising results have been obtained in terms of initial coulombic efficiency, high reversible 
Fig. 11 Schematic process for fabricating the Si/graphene nanocomposite [52]
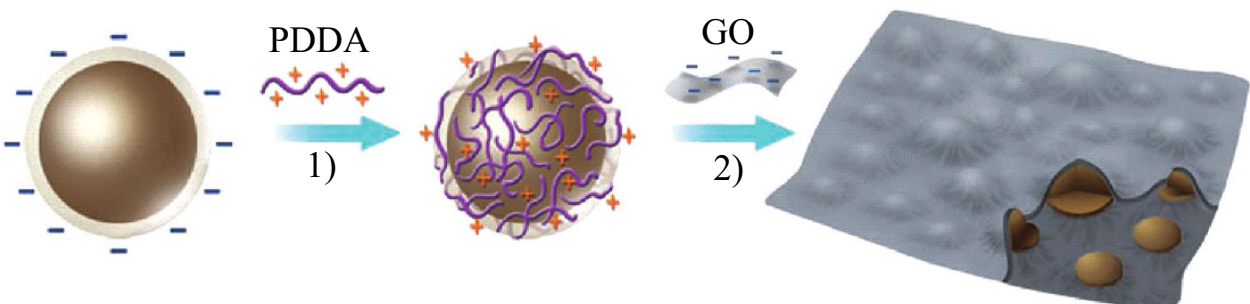

(a)

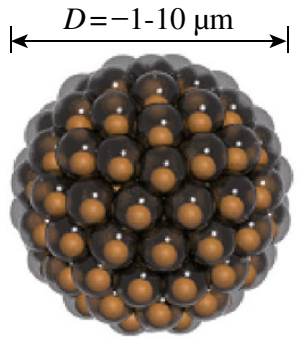

(b)

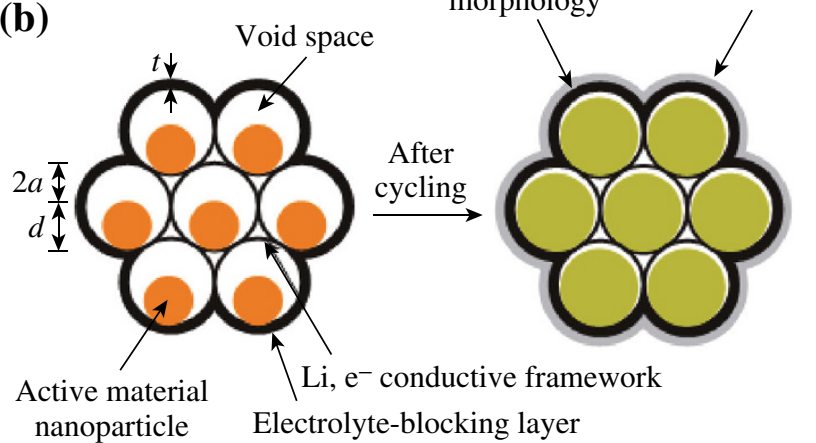

(c)

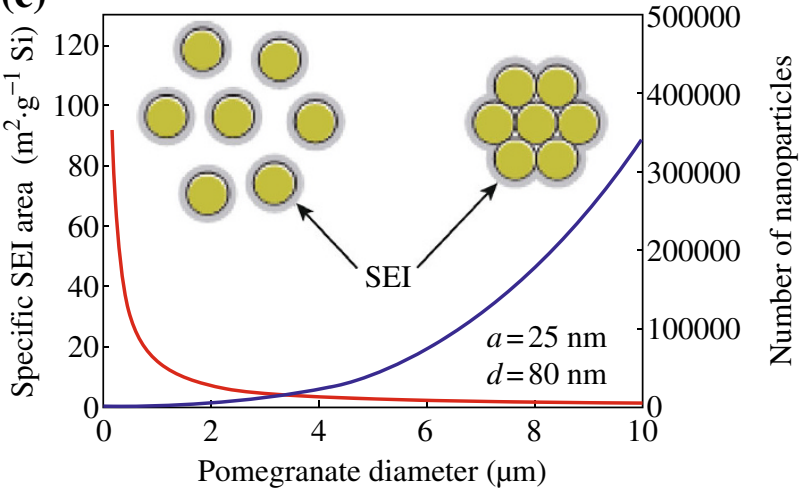

Fig. 12 Schematic of the pomegranate-inspired design. 3D view (a) and simplified 2D cross-sectional view (b) of one pomegranate microparticle before and after electrochemical cycling (in the lithiated state). c Calculated surface area in contact with electrolyte (specific SEI area) and the number of primary nanoparticles in one pomegranate particle versus its diameter [59]

capacity, and cycling stability. Carbon is expected to play an important role in electrode reliability owing to its relative softness, small volume change during $\mathrm{Li}$ insertion, and good electronic conductivity. Graphene is a good candidate to host active nanoparticles among the various carbon materials because of its high surface area, superior electrical conductivity, and excellent mechanical flexibility [46-49]. In general, graphene sheets in the as-obtained hybrid materials can function as supports of active materials and provide conductive channels for electrons through the electrodes. Chou et al. prepared Si/graphene composite by sample mixing of nano-sized $\mathrm{Si}$ and graphene [50]. The improved cycling stability is attributed to the good mechanical properties and conductivity provided by graphene. Zhao et al. reported $\mathrm{Si} /$ graphene composite constructed with a graphitic scaffold with in-plane carbon vacancy defects [51]. Figure 10 shows the schematic drawing. They demonstrated the beneficial effects of nanometer-sized in-plane vacancies on ion transport for use in a 3D graphitic scaffold that can be fabricated into hybrid materials with a combination of power capability and storage capacity for battery electrode applications. Zhou et al. used a self-assembly approach to encapsulate $\mathrm{Si}$ nanoparticles in graphene via electrostatic force (Fig. 11) [52]. A good cycling performance of the composite had been observed. The capacity reached $1,205 \mathrm{mAh} \mathrm{g}^{-1}$ after 150 cycles.

\subsection{Hollow and Yolk-Shell Structure Composites}

Pioneering works have shown that decreasing the feature size to the nanoscale allows for the material to withstand the large (de) lithiation strains without fracture. However, the cycle life of nano-sized silicon is still limited due to the unstable SEI on the surface. Recently, hollow and yolkshell structures of $\mathrm{Si}$ composites, coated with conductive materials, have been shown to be an efficient way to solve the problem [53-58].

Cui et al. demonstrated a novel secondary structure for $\mathrm{Si}$ anodes [59], as shown in Fig. 12. Such a design has multiple advantages: (1) the nano-sized primary particle and the well-defined internal void space allow the silicon to expand; (2) the carbon framework functions as an electrical highway so that all nanoparticles are electrochemically active; (3) carbon completely encapsulates the entire secondary particle, limiting the SEI film formation to the outer surface, which not only limits the amount of SEI, but also 
Fig. 13 Electrochemical characterization of $\mathrm{Si}$ pomegranate anodes. a Reversible delithiation capacity for the first 1,000 galvanostatic cycles of the $\mathrm{Si}$ pomegranate and other structures tested under the same conditions. Coulombic efficiency is plotted for the silicon pomegranate only. The rate was $\mathrm{C} / 20$ for the first cycle and $\mathrm{C} / 2$ for later cycles. b Voltage profiles for the $\mathrm{Si}$ pomegranate plotted for the 3rd, 250th, 500th, 750th, and 1,000th cycles. c High areal mass loading test (up to $3.12 \mathrm{mg} \mathrm{cm}^{-2}$ active material) of silicon pomegranate anodes [59]
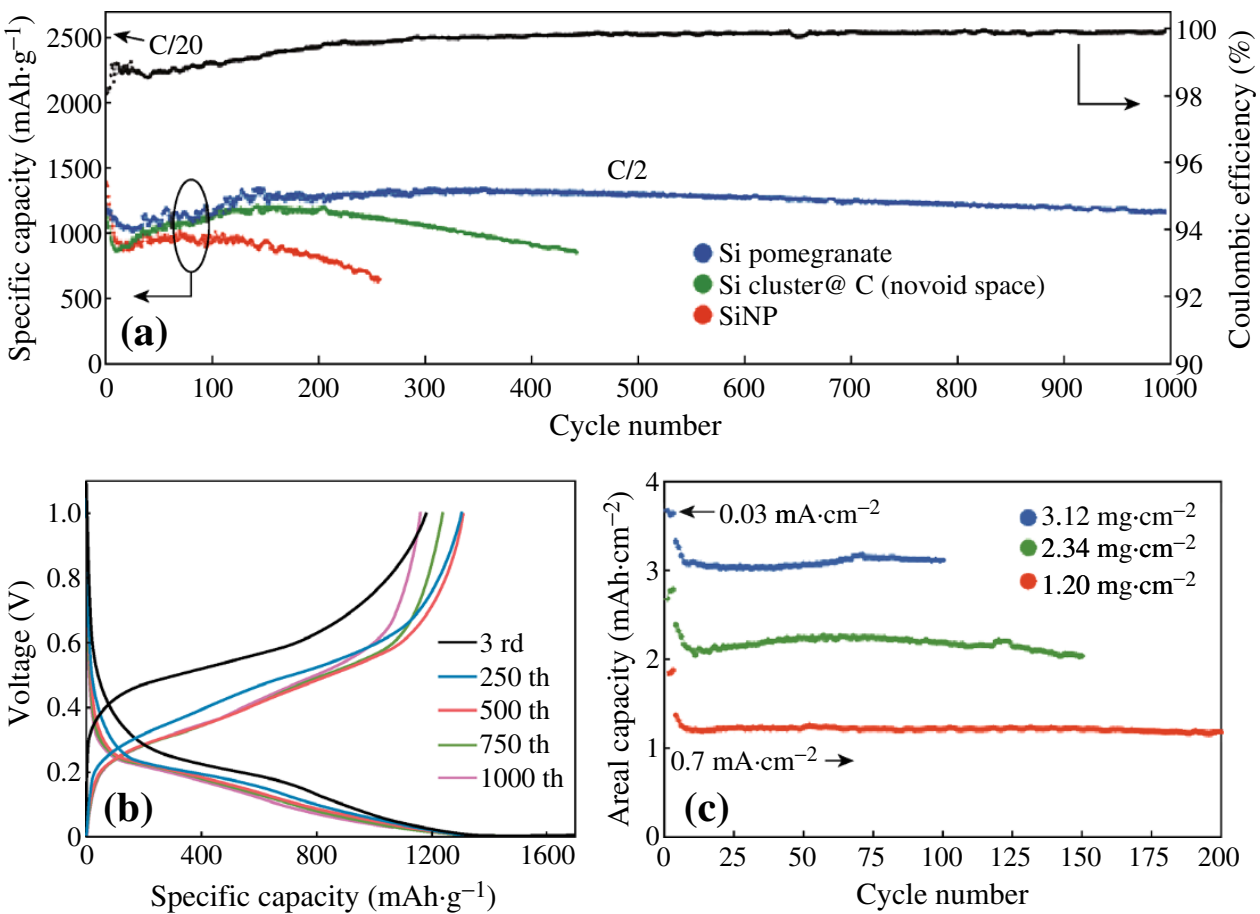

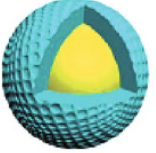

$\mathrm{PS} @ \mathrm{SiO}_{2}$

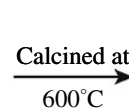

$600^{\circ} \mathrm{C}$

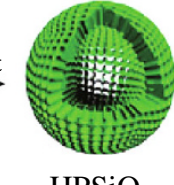

$\operatorname{Mg}$ NPs $(60 \mathrm{~nm})$ $\mathrm{H}_{2} / \mathrm{Ar} 650^{\circ} \mathrm{C}$

$\mathrm{HPSiO}_{2}$

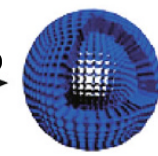

HPSi
Fig. 14 Scheme of preparing hollow porous Si nanoparticles [60]

retains the internal void space for silicon expansion; and (4) the dilemmas of high surface area and low tap density, which are introduced when using nano-sized primary features, are partially solved. As shown in Fig. 13a, its reversible capacity reaches $2,350 \mathrm{mAh} \mathrm{g}^{-1}$ at a rate of $\mathrm{C} / 20$, and after 1,000 cycles, over $1,160 \mathrm{mAh} \mathrm{g}^{-1}$ capacity can be reached. The average coulombic efficiency from the 500th to 1000th cycles of the Si pomegranate is as high as $99.87 \%$, indicating that SEI is very stable.

Chen et al. reported a facile approach to fabricate monodisperse hollow porous $\mathrm{Si}$ (HPSi) nanoparticles (ca. $120 \mathrm{~nm}$ ) by the magnesiothermic reduction of hollow porous $\mathrm{SiO}_{2}\left(\mathrm{HPSiO}_{2}\right)$ nanoparticles [60]. This step was followed by Ag coating the nanoparticle for conductivity enhancement (Fig. 14). The HPSi anode showed a high specific reversible capacity $\left(3,762 \mathrm{mAh} \mathrm{g}^{-1}\right)$, good cycle stability (over $93 \%$ capacity retention after 99 cycles), and high rate performance (over 2,000 $\mathrm{mAh} \mathrm{g}^{-1}$ at a current density $4,000 \mathrm{~mA} \mathrm{~g}^{-1}$ ).

\subsection{Effect of Binder}

Recent studies have also shown that many important battery characteristics, including stability and irreversible capacity losses, are critically dependent on the binder's properties [61-64]. It is found that polymers containing carboxy groups, such as polyacrylic acid (PAA) and carboxymethyl cellulose (CMC), demonstrate promising characteristics as binders for Si-based anodes $[65,66]$. The polar hydrogen bonds between the carboxy groups of the binder and the $\mathrm{SiO}_{2}$ on the $\mathrm{Si}$ surface are proposed to exhibit a self-healing effect and reform if locally broken.

Kovalenko et al. used alginate as the binder of nano-Si electrode, which yielded a remarkably stable battery anode [67]. As shown in Fig. 15, charge-discharge cycling performance with $\mathrm{Li}$ insertion capacity limited to $1,200 \mathrm{mAh}$ $\mathrm{g}^{-1}$ shows stable anode performance for more than 1,300 cycles. At a current density of $4,200 \mathrm{~mA} \mathrm{~g}^{-1}$, the reversible $\mathrm{Li}$ extraction specific capacity of an alginate-based $\mathrm{Si}$ anode ranges from 1,700 to 2,000 $\mathrm{mAh} \mathrm{g}^{-1}$ (Fig. 15b). At a smaller current density of $140 \mathrm{~mA} \mathrm{~g}^{-1}$ (Fig. 3c), the specific capacity of the $\mathrm{Si}$ anode reaches $3,040 \mathrm{mAh} \mathrm{g}^{-1}$. The good battery performance can be contributed to several reasons. First, a very weak binder-electrolyte interaction prevents access of the solvent molecules to the Si-binder boundary. Second, the alginate can provide access of $\mathrm{Li}$ ions to the $\mathrm{Si}$ surface because it is an ion conductor. Third, it also can assist in building a deformable and stable SEI on the Si surface. 


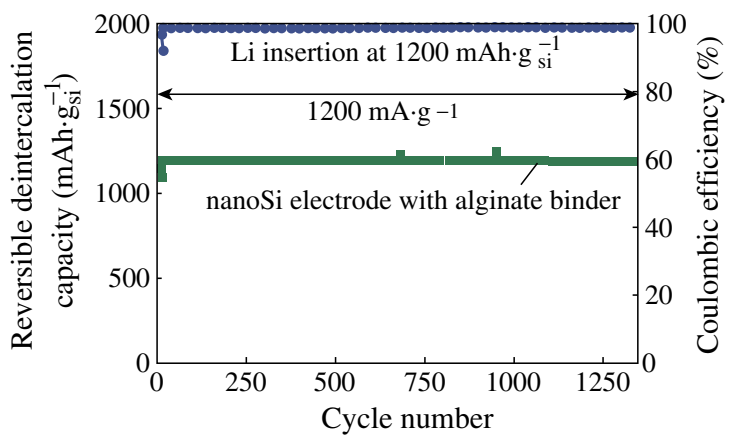

(a)

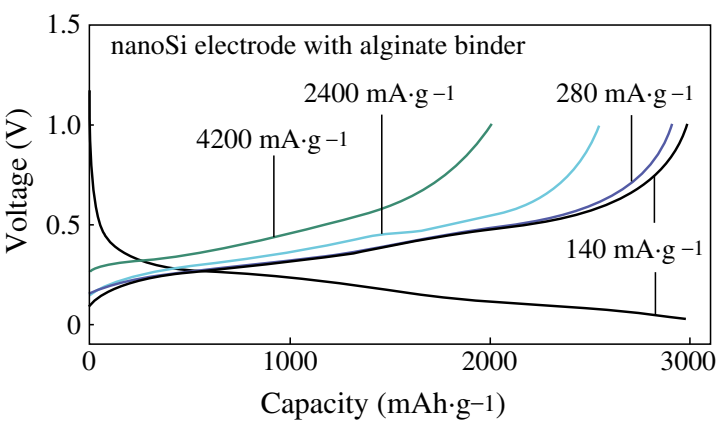

(c)

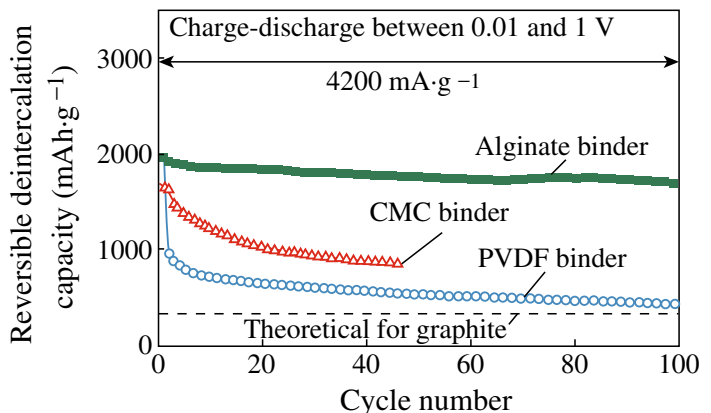

(b)

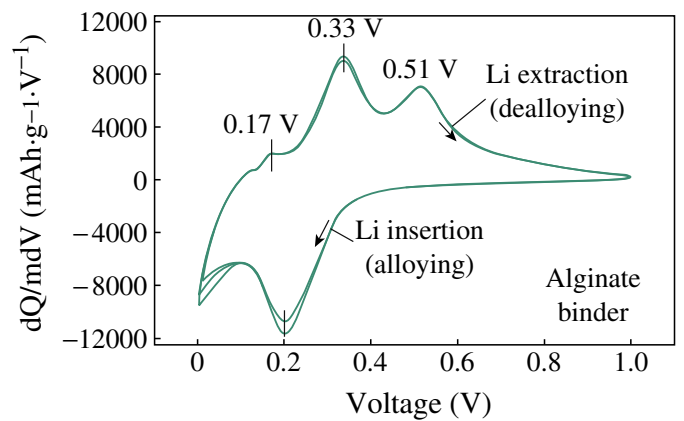

(d)

Fig. 15 Electrochemical performance of alginate-based nano-Si electrodes. a Reversible Li-extraction capacity and CE of the nano-Si electrodes versus cycle number for $\mathrm{Li}$ insertion level fixed to $1,200 \mathrm{mAh} \mathrm{g}^{-1} \mathrm{Si}$. b Reversible Li-extraction capacity of nano-Si electrodes with alginate, CMC, and P VDF binders versus cycle number collected for the current density of 4,200 mA g $\mathrm{g}^{-1}$ for cells cycled in the potential window of $0.01-1 \mathrm{~V}$ versus $\mathrm{Li} / \mathrm{Li}^{+}$. c Galvanostatic discharge profiles of the nano-Si electrode at different current densities between 0 and $1 \mathrm{~V}$. d Differential capacity curves of the nano-Si electrode in the potential window of $0-1 \mathrm{~V}$ versus $\mathrm{Li}^{2} / \mathrm{Li}^{+}$collected at the rate of $0.025 \mathrm{mV} \mathrm{s}^{-1}$ after the first galvanostatic charge-discharge cycle [67]

\section{Summary and Outlook}

To sum up, we have briefly reviewed the recent advances in the studies on the Si anode materials. Although Si has an extremely high theoretical capacity, the bulk Si powders have demonstrated very poor electrochemical performance, due to the large volume variation during the charge and discharge processes, resulting in pulverization and delamination from the current collectors. Reducing the materials size to nanoscale is an effective method to solve this problem. For example, diverse nanostructured Si (0D, 1D, 2D, and 3D), Si/metal nanocomposites, and $\mathrm{Si} / \mathrm{C}$ nanocomposites show improved battery performance. However, these methods cannot form stable SEI on the surface of $\mathrm{Si}$, which is another important reason for the failure of $\mathrm{Si}$ anode. Experimental results show that surface modification is a practical method to control the formation of SEI. For example, hollow and yolk-shell structures of Si composites, coated with conductive materials, show excellent battery performance.

Although considerable advances have been achieved in the last decade to design and synthesize Si-based anode materials, for the practical application composite, several fundamental issues remain to be solved. First, nanomaterials have the genuine potential to make a significant impact on the performance of LIBs. However, they are certainly not a panacea. For example, coulombic efficiency of nanopowder is very low, because the high electrolyte/electrode surface area leads to more significant side reactions. Further, the density of nanopowder is generally less than the same material formed from micrometer-sized particles, which would reduce the volumetric energy density of battery. The problem mentioned above should be solved in the subsequent researches. Possible strategies include the following: (1) fabricating hierarchical nano/micrometer-sized structures to improve the tap density of electrode materials and building ultrathick electrodes to enhance the overall volumetric capacity [68-70]; (2) adopting surface coating to avoid unnecessary side reactions [71, 72]; and (3) using advanced manufacturing methods, such as $3 \mathrm{D}$ printing, to fabricate electrodes with 3D battery architecture by optimizing the structures of both anodes and cathodes [73, 74]. 
In addition, the electrolyte offers a promising field for more extensive research efforts. It is found that the electrolyte containing $\mathrm{VC}$ or FEC has been recognized to favor the formation of more stable SEI film. Furthermore, the fabrication cost of nano-structured $\mathrm{Si}$ remains high and needs to be reduced for its practical applications.

Acknowledgments This work is partially supported by Beijing High-level Oversea Talent Project and the strategic research grant "Laser interference process of silver nanostructures for surface enhanced Raman spectroscopy and environment application" (KZ201410005001) of Beijing Nature Science Foundation, the P. R. China.

Open Access This article is distributed under the terms of the Creative Commons Attribution License which permits any use, distribution, and reproduction in any medium, provided the original author(s) and the source are credited.

\section{References}

1. B. Dunn, H. Kamath, J.M. Tarascon, Electrical energy storage for the grid: a battery of choices. Science 334(6058), 928-935 (2011). doi:10.1126/science.1212741

2. K. Kang, Y.S. Meng, J. Bréger, C.P. Grey, G. Ceder, Electrodes with high power and high capacity for rechargeable lithium batteries. Science 311(5763), 977-980 (2006). doi:10.1126/sci ence. 1122152

3. C.M. Park, J.H. Kim, H. Kim, H.J. Sohn, Li-alloy based anode materials for Li secondary batteries. Chem. Soc. Rev. 39(8), 3115-3141 (2010). doi:10.1039/b919877f

4. N.S. Choi, Z. Chen, S.A. Freunberger, X. Ji, Y.K. Sun, K. Amine, G. Yushin, L.F. Nazar, J. Cho, P.G. Bruce, Challenges facing lithium batteries and electrical double-layer capacitors. Angew. Chem. Int. Ed. 51(40), 9994-10024 (2012). doi:10.1002/anie. 201201429

5. L. Wang, X. He, J. Li, W. Sun, J. Gao, J. Guo, C. Jiang, Nanostructured phosphorus composite as high-capacity anode materials for lithium batteries. Angew. Chem. Int. Ed. 51(36), 9034-9037 (2012). doi:10.1002/anie.201204591

6. A.N. Dey, Electrochemical alloying of lithium in organic electrolytes. J. Electrochem. Soc. 118(10), 1547-1549 (1971). doi:10. $1149 / 1.2407783$

7. X. Su, Q. Wu, J. Li, X. Xiao, A. Lott, W. Lu, B.W. Sheldon, J. Wu, Silicon-based nanomaterials for lithium-ion batteries: A review. Adv. Energy Mater. 4(1), 1-23 (2014). doi:10.1002/ aenm.201300882

8. Y.X. Yin, L.J. Wan, Y.G. Guo, Silicon-based nanomaterials for lithium-ion batteries. Chin. Sci. Bull. 57(32), 4104-4110 (2012). doi:10.1007/s11434-012-5017-2

9. B. Gao, S. Sinha, L. Fleming, O. Zhou, Alloy formation in nanostructured silicon. Adv. Mater. 13(11), 816-819 (2001). doi:10.1002/1521-4095(200106)13:11<816:AID-ADMA816>3. $0 . \mathrm{CO} ; 2-\mathrm{P}$

10. H. Li, X. Huang, L. Chen, G. Zhou, Z. Zhang, D. Yu, Y.J. Mo, N. Pei, The crystal structural evolution of nano-Si anode caused by lithium insertion and extraction at room temperature. Solid State Ionics 135(1-4), 181-191 (2000). doi:10.1016/S01672738(00)00362-3

11. P. Limthongkul, Y.I. Jang, N.J. Dudney, Y.M. Chiang, Electrochemically-driven solid-state amorphization in lithium-silicon alloys and implications for lithium storage. Acta Mater. 51(4), 1103-1113 (2003). doi:10.1016/S1359-6454(02)00514-1

12. A. Netz, R.A. Huggins, W. Weppner, The formation and properties of amorphous silicon as negative electrode reactant in lithium systems. J. Power Sources 119-121, 95-100 (2003). doi:10.1016/S0378-7753(03)00132-0

13. M.N. Obrovac, L. Christensen, Structural changes in silicon anodes during lithium insertion/extraction. Electrochem. SolidState Lett. 7(5), A93-A96 (2004). doi:10.1149/1.1652421

14. T.D. Hatchard, J.R. Dahn, In-situ XRD and electrochemical study of the reaction of lithium with amorphous silicon. J. Electrochem. Soc. 151(6), A838-A842 (2004). doi:10.1149/1.1739217

15. J. Li, J.R. Dahn, An in situ X-ray diffraction study of the reaction of Li with crystalline Si. J. Electrochem. Soc. 154(3), A156A161 (2007). doi:10.1149/1.2409862

16. J.H. Ryu, J.W. Kim, Y.E. Sung, S.M. Oh, Failure Modes of silicon powder negative electrode in lithium secondary batteries. Electrochem. Solid-State Lett. 7(10), A306-A309 (2004). doi:10. $1149 / 1.1792242$

17. C.J. Wen, R.A. Huggins, Chemical diffusion in intermediate phases in the lithium-silicon system. J. Solid-State Chem. 37(3), 271-278 (1981). doi:10.1016/0022-4596(81)90487-4

18. J.H. Kim, PhD Dissertation, Seoul National University, 2006

19. Y. Oumellal, N. Delpuech, D. Mazouzi, N. Dupré, J. Gaubicher, P. Moreau, P. Soudan, B. Lestriez, D. Guyomard, The failure mechanism of nano-sized Si-based negative electrodes for lithium ion batteries. J. Mater. Chem. 21(17), 6201-6208 (2011). doi:10. 1039/c1jm10213c

20. C.K. Chan, H. Peng, G. Liu, K. McIlwrath, X.F. Zhang, R.A. Huggins, Y. Cui, High-performance lithium battery anodes using silicon nanowires. Nat. Nanotechnol. 3(1), 31-35 (2008). doi:10. 1038/nnano.2007.411

21. H. Wu, G. Chan, J.W. Choi, I. Ryu, Y. Yao, M.T. McDowell, S.W. Lee, A. Jackson, Y. Yang, L. Hu, Y. Cui, Stable cycling of double-walled silicon nanotube battery anodes through solidelectrolyte interphase control. Nat. Nanotechnol. 7(5), 310-315 (2012). doi:10.1038/nnano.2012.35

22. P.G. Bruce, B. Scrosati, J.M. Tarascon, Nanomaterials for rechargeable lithium batteries. Angew. Chem. Int. Ed. 47(16), 2930-2946 (2008). doi:10.1002/anie.200702505

23. H. Li, X. Huang, L. Chen, Z. Wu, Y. Liang, A high capacity nano Si composite anode material for lithium rechargeable batteries. Electrochem. Solid-State Lett. 2(11), 547-549 (1999). doi:10. $1149 / 1.1390899$

24. H. Kim, M. Seo, M.-H. Park, J. Cho, A critical size of silicon nano-anodes for lithium rechargeable batteries. Angew. Chem. Int. Ed. 49(12), 2146-2149 (2010). doi:10.1002/anie.200906287

25. T. Song, J. Xia, J.H. Lee, D.H. Lee, M.S. Kwon, J.M. Choi, J. Wu, S.K. Doo, H. Chang, W. Park, D.S. Zang, H. Kim, Y.G. Huang, K.C. Hwang, J.A. Rogers, U. Paik, Arrays of sealed silicon nanotubes as anodes for Lithium ion batteries. Nano Lett. 10(5), 1710-1716 (2010). doi:10.1021/n1100086e

26. S. Ohara, J. Suzuki, K. Sekine, T. Takamura, A thin film silicon anode for Li-ion batteries having a very large specific capacity and long cycle life. J. Power Sources 136(2), 303-306 (2004). doi:10.1016/j.jpowsour.2004.03.014

27. K.L. Lee, J.Y. Jung, S.W. Lee, H.S. Moon, J.W. Park, Electrochemical characteristics of $a$-Si thin film anode for Li-ion rechargeable batteries. J. Power Sources 129(2), 270-274 (2004). doi:10.1016/j.jpowsour.2003.10.013

28. M.S. Park, G.X. Wang, H.K. Liu, S.W. Dou, Electrochemical properties of Si thin film prepared by pulsed laser deposition for lithium ion micro-batteries. Electrochim. Acta 51(25), 5246-5249 (2006). doi:10.1016/j.electacta.2006.01.045

29. J.P. Maranchi, A.F. Hepp, P.N. Kumta, High capacity, reversible silicon thin-film anodes for lithium-ion batteries. Electrochem. 
Solid-State Lett. 6(9), A198-A201 (2003). doi:10.1149/1. 1596918

30. H. Kim, B. Han, J. Choo, J. Cho, Three-dimensional porous silicon particles for use in high-performance lithium secondary batteries. Angew. Chem. 120(52), 10305-10308 (2008). doi:10. 1002/ange. 200804355

31. D. Ma, Z. Cao, H. Wang, X. Huang, L. Wang, X. Zhang, Threedimensionally ordered macroporous $\mathrm{FeF}_{3}$ and its in situ homogenous polymerization coating for high energy and power density lithium ion batteries. Energy Environ. Sci. 5(9), 8538-8542 (2012). doi:10.1039/c2ee22568a

32. D. Ma, S. Yuan, Z. Cao, Three-dimensionally macroporous graphene-supported $\mathrm{Fe}_{3} \mathrm{O}_{4}$ composite as anode material for $\mathrm{Li}$ ion batteries with long cycling life and ultrahigh rate capability. Chin. Sci. Bull. 59(17), 2017-2023 (2014). doi:10.1007/s11434-0140307-5

33. H. Zhang, X. Yu, P.V. Braun, Three-dimensional bicontinuous ultrafast-charge and -discharge bulk battery electrodes. Nat. Nanotechnol. 6(5), 277-281 (2011). doi:10.1038/nnano.2011.38

34. J.H. Pikul, H.G. Zhang, J. Cho, P.V. Braun, W.P. King, Highpower lithium ion microbatteries from interdigitated threedimensional bicontinuous nanoporous electrodes. Nat. Commun. 4, 1732 (2013). doi:10.1038/ncomms 2747

35. H. Jia, P. Gao, J. Yang, J. Wang, Y. Nuli, Z. Yang, Novel threedimensional mesoporous silicon for high power lithium-ion battery anode material. Adv. Energy Mater. 1(6), 1036-1039 (2011). doi:10.1002/aenm.201100485

36. A. Esmanski, G.A. Ozin, Silicon inverse-opal-based macroporous materials as negative electrodes for lithium ion batteries. Adv. Funct. Mater. 19(12), 1999-2010 (2009). doi:10.1002/adfm. 200900306

37. B.M. Bang, J.I. Lee, H. Kim, J. Cho, S.J. Park, High-performance macroporous bulk silicon anodes synthesized by template-free chemical etching. Adv. Energy Mater. 2(7), 878-883 (2012). doi:10.1002/aenm.201100765

38. W.R. Liu, Z.Z. Guo, W.S. Young, D.T. Shieh, H.C. Wu, M.H. Yang, N.L. Wu, Effect of electrode structure on performance of $\mathrm{Si}$ anode in Li-ion batteries: $\mathrm{Si}$ particle size and conductive additive. J. Power Sources 140(1), 139-144 (2005). doi:10.1016/ j.jpowsour.2004.07.032

39. C.K. Huang, S. Surampudi, A.I. Attia, G. Halpert, US Pat. 5, 294-503 (1994)

40. H. Kim, J. Choi, H.J. Sohn, T. Kang, The insertion mechanism of lithium into $\mathrm{Mg}_{2} \mathrm{Si}$ anode material for Li-Ion batteries. J. Electrochem. Soc. 146(12), 4401-4405 (1999). doi:10.1149/1.1392650

41. T. Moriga, K. Watanabe, D. Tsuji, S. Massaki, I. Nakabayashi, Reaction mechanism of metal silicide $\mathrm{Mg}_{2} \mathrm{Si}$ for $\mathrm{Li}$ insertion. J. Solid State Chem. 153(2), 386-390 (2000). doi:10.1006/jssc. 2000.8787

42. G.A. Roberts, E.J. Cairns, J.A. Reimer, Magnesium silicide as a negative electrode material for lithium-ion batteries. J. Power Sources 110(2), 424-429 (2002). doi:10.1016/S0378-7753 (02)00207-0

43. J. Wolfenstine, $\mathrm{CaSi}_{2}$ as an anode for lithium-ion batteries. J. Power Sources 124(1), 241-245 (2003). doi:10.1016/S03787753(03)00731-6

44. G.X. Wang, L. Sun, D.H. Bradhurst, S. Zhong, S.X. Dou, H.K. Liu, Innovative nanosize lithium storage alloys with silica as active centre. J. Power Sources 88(2), 278-281 (2000). doi:10. 1016/S0378-7753(00)00385-2

45. S.Y. Chew, Z.P. Guo, J.Z. Wang, J. Chen, P. Munroe, S.H. Ng, L. Zhao, H.K. Liu, Novel nano-silicon/polypyrrole composites for lithium storage. Electrochem. Commun. 9(5), 941-946 (2007). doi:10.1016/j.elecom.2006.11.028

46. X. Fan, W. Peng, Y. Li, X.Y. Li, S.L. Wang, G.L. Zhang, F.B. Zhang, Deoxygenation of exfoliated graphite oxide under alkaline conditions: a green route to graphene preparation. Adv. Mater. 20(23), 4490-4493 (2008). doi:10.1002/adma.200801306

47. Z. Wang, D. Xu, Y. Huang, Z. Wu, L.M. Wang, X.B. Zhang, Facile, mild and fast thermal-decomposition reduction of graphene oxide in air and its application in high-performance lithium batteries. Chem. Commun. 48(7), 976-978 (2012). doi:10.1039/ $\mathrm{c} 2 \mathrm{cc} 16239 \mathrm{c}$

48. X.L. Huang, R.Z. Wang, D. Xu, Z.L. Wang, H.G. Wang, J.J. Xu, Z. Wu, Q.C. Liu, Y. Zhang, X.B. Zhang, Homogeneous CoO on graphene for binder-free and ultralong-life lithium ion batteries. Adv. Funct. Mater. 23(35), 4345-4353 (2013). doi:10.1002/adfm. 201203777

49. Y.G. Zhou, J.J. Chen, F. Wang, Z.H. Sheng, X.H. Xia, A facile approach to the synthesis of highly electroactive Pt nanoparticles on graphene as an anode catalyst for direct methanol fuel cells. Chem. Commun. 46(32), 5951-5953 (2010). doi:10.1039/ $\mathrm{c} 0 \mathrm{cc} 00394 \mathrm{~h}$

50. S.L. Chou, J.Z. Wang, M. Choucair, H.K. Liu, J.A. Stride, S.X. Dou, Enhanced reversible lithium storage in a nanosize silicon/ graphene composite. Electrochem. Commun. 12(2), 303-306 (2010). doi:10.1016/j.elecom.2009.12.024

51. X. Zhao, C.M. Hayner, M.C. Kung, H.H. Kung, In-plane vacancy-enabled high-power Si-graphene composite electrode for lithium-ion batteries. Adv. Energy Mater. 1(6), 1079-1084 (2011). doi:10.1002/aenm.201100426

52. X. Zhou, Y.X. Yin, L.J. Wan, Y.G. Guo, Self-assembled nanocomposite of silicon nanoparticles encapsulated in graphene through electrostatic attraction for lithium ion batteries. Adv. Energy Mater. 2(9), 1086-1090 (2012). doi:10.1002/aenm. 201200158

53. H. Wu, G. Chan, J.W. Choi, I. Ryu, Y. Yao, M.T. McDowell, S.W. Lee, A. Jackson, Y. Yang, L. Hu, Y. Cui, Stable cycling of double-walled silicon nanotube battery anodes through solidelectrolyte interphase control. Nat. Nanotech. 7(5), 310-315 (2012). doi:10.1038/nnano.2012.35

54. N. Liu, H. Wu, M.T. McDowell, Y. Yao, C.M. Wang, Y. Cui, A yolk-shell design for stabilized and scalable Li-ion battery alloy anodes. Nano Lett. 12(6), 3315-3321 (2012). doi:10.1021/ $\mathrm{nl} 3014814$

55. X. Li, P. Meduri, X. Chen, W. Qi, M.H. Engelhard, W. Xu, F. Ding, J. Xiao, W. Wang, C.M. Wang, J.G. Zhang, J. Liu, Hollow core-shell structured porous $\mathrm{Si}-\mathrm{C}$ nanocomposites for $\mathrm{Li}$-ion battery anodes. J. Mater. Chem. 22(22), 11014-11017 (2012). doi:10.1039/c2jm31286g

56. S. Chen, M.L. Gordin, R. Yi, G. Howlett, H. Sohn, D.H. Wang, Silicon core-hollow carbon shell nanocomposites with tunable buffer voids for high capacity anodes of lithium-ion batteries. Phys. Chem. Chem. Phys. 14(37), 12741-12745 (2012). doi:10. 1039/c2cp42231j

57. Y. Park, N.S. Choi, S. Park, S. Woo, S.H. Sim, S. Jang, B.Y. Oh, S.M. Park, S. Cho, K.T. Lee, Si-encapsulating hollow carbon electrodes via electroless etching for lithium-ion batteries. Adv. Energy Mater. 3(2), 206-212 (2013). doi:10.1002/aenm. 201200389

58. B. Wang, X. Li, X. Zhang, B. Luo, Y.B. Zhang, L.J. Zhi, Contactengineered and void-involved silicon/carbon nanohybrids as lithium-ion-battery anodes. Adv. Mater. 25(26), 3560-3565 (2013). doi:10.1002/adma.201300844

59. N. Liu, Z. Lu, J. Zhao, M.T. McDowell, H.W. Lee, W.T. Zhao, Y. Cui, A pomegranate-inspired nanoscale design for large-volume-change lithium battery anodes. Nat. Nanotechnol. 9(3), 187-192 (2014). doi:10.1038/NNANO.2014.6

60. D. Chen, X. Mei, G. Ji, M. Lu, J. Xie, J. Lu, J.Y. Lee, Reversible lithium-ion storage in silver-treated nanoscale hollow porous silicon particles. Angew. Chem. Int. Ed. 51(10), 2409-2413 (2012). doi:10.1002/anie.201107885 
61. J.S. Bridel, T. Azais, M. Morcrette, J.M. Tarascon, D. Larcher, Key parameters governing the reversibility of Si/Carbon/CMC electrodes for li-ion batteries. Chem. Mater. 22(3), 1229-1233 (2010). doi:10.1021/cm902688w

62. L. Fransson, T. Eriksson, K. Edström, T. Gustafsson, J.O. Thomas, Influence of carbon black and binder on Li-ion batteries. J. Power Sources 101(1), 1-9 (2001). doi:10.1016/S03787753(01)00481-5

63. S.S. Zhang, T.R. Jow, Study of poly (acrylonitrile-methyl methacrylate) as binder for graphite anode and $\mathrm{LiMn}_{2} \mathrm{O}_{4}$ cathode of Li-ion batteries. J. Power Sources 109(2), 422-426 (2002). doi:10.1016/S0378-7753(02)00107-6

64. D. Guy, B. Lestriez, D. Guyomard, New composite electrode architecture and improved battery performance from the smart use of polymers and their properties. Adv. Mater. 16(6), 553-557 (2004). doi:10.1002/adma.200306075

65. D. Mazouzi, B. Lestriez, L. Roue, D. Guyomard, Silicon composite electrode with high capacity and long cycle life. Electrochem. Solid-State Lett. 12(11), A215-A218 (2009). doi:10.1149/ 1.3212894

66. A. Magasinski, B. Zdyrko, I. Kovalenko, B. Hertzberg, R. Burtovyy, C.F. Huebner, T.F. Fuller, I. Luzinov, G. Yushin, Toward efficient binders for Li-ion battery Si-based anodes: polyacrylic acid. ACS Appl. Mater. Inter. 2(11), 3004-3010 (2010). doi:10. 1021/am100871y

67. I. Kovalenko, B. Zdyrko, A. Magasinski, B. Hertzberg, Z. Milicev, R. Burtovyy, I. Luzinov, G. Yushin, A major constituent of brown algae for use in high-capacity Li-ion batteries. Science 334(6052), 75-79 (2011). doi:10.1126/science.1209150
68. M.Y. Wu, J.E.C. Sabisch, X.Y. Song, A.M. Minor, V.S. Battaglia, G. Liu, In situ formed Si nanoparticle network with micronsized $\mathrm{Si}$ particles for lithium-ion battery anodes. Nano Lett. 13(11), 5397-5402 (2013). doi:10.1021/n1402953h

69. P.J. Zhang, L.B. Wang, J. Xie, L.W. Su, C.A. Ma, Micro/nanocomplex-structure SiOx-PANI-Ag composites with homogeneously-embedded $\mathrm{Si}$ nanocrystals and nanopores as high-performance anodes for lithium ion batteries. J. Mater. Chem. A 2(11), 3776-3782 (2014). doi:10.1039/c3ta14498d

70. H.L. Zhang, Y. Zhang, X.G. Zhang, F. Li, C. Liu, J. Tan, H.M. Cheng, Urchin-like nano/micro hybrid anode materials for lithium ion battery. Carbon 44(13), 2778-2784 (2006). doi:10.1016/ j.carbon.2006.03.029

71. M. Yoshio, H. Wang, K. Fukuda, T. Umeno, N. Dimov, Z. Ogumi, Carbon-coated $\mathrm{Si}$ as a lithium-ion battery anode material. J. Electrochem. Soc. 149(12), A1598-A1603 (2002). doi:10. $1149 / 1.1518988$

72. H.Y. Lee, S.M. Lee, Carbon-coated nano-Si dispersed oxides/ graphite composites as anode material for lithium ion batteries. Electrochem. Commun. 6(5), 465-469 (2004). doi:10.1016/j.ele com.2004.03.005

73. A.J. Lopes, E. MacDonald, R.B. Wicker, Integrating stereolithography and direct print technologies for 3D structural electronics fabrication. Rapid Prototyping J. 18(2), 129-143 (2012). doi:10.1108/13552541211212113

74. L.T. Le, M.H. Ervin, H. Qiu, B.E. Fuchs, W.Y. Lee, Graphene supercapacitor electrodes fabricated by inkjet printing and thermal reduction of graphene oxide. Electrochem. Commun. 13(4), 355-358 (2011). doi:10.1016/j.elecom.2011.01.023 